\title{
Environmental performance assessment of the building construction process during architectural detailing
}

\author{
B. Metin \& A. Tavil \\ Department of Architecture, Faculty of Architecture, \\ Istanbul Technical University, Turkey
}

\begin{abstract}
Environmental impacts start to arise during the construction process initially. Despite the large amount of construction activities in Turkey, environmental performance of the construction process is not a familiar issue for the construction industry. The conventional structure of the construction sector and the lack of quantitative data for environmental impacts also makes it difficult to analyse the construction process with environmental considerations. This paper presents a model, which provides an environmental assessment of the building construction process during architectural detailing. The model is developed based on the argument that the inputs of the construction process have a direct relationship with the environmental impacts of the process. Therefore, the relationships between construction technologies, which are the main inputs of the process, and environmental performance parameters form the basis of the model. The model proposes a construction technology classification and a decision hierarchy for the environmental parameters related with the construction process. Integrated multi criteria decision-making methods are used for the assessment. Decision makers define the weights of the parameters by using the Fuzzy Analytical Hierarchical Process (FAHP) and sort design alternatives by using the Fuzzy Technique for Order Preference by Similarity to Ideal Solution (FTOPSIS) methods. In the context of the paper, different floor alternatives of an office building project are assessed to demonstrate the use of the model and to identify advantages and limitations of the assessment process.

Keywords: architectural detailing, construction process, construction technology, environmental performance.
\end{abstract}




\section{Introduction}

The rapid growth of the construction activities due to the urban renewal process in Turkey raise concerns over environmental consequences that buildings are responsible for. Assessing and analyzing environmental performance of buildings starting from the design phase becomes more important than ever to control the outcomes of each phase of a building life cycle. However, only the use/operation phase is taken into account by the Turkish construction industry, when environmental issues are under consideration. It is mostly because of the duration of the use phase, which is the longest period of a building life cycle. However, a building starts to originate physically at the construction process through a variety of activities performed at different stages of construction, which means adverse impacts on environment also start to arise. It is estimated that the construction process is responsible for $15 \%$ of the environmental impacts of all building life cycle phases [1]. Hence, it should also be taken into account for a holistic achievement regarding with the environmental performance of buildings.

The assessment of the construction process in the context of environmental performance is difficult based on some grounds, which are the uniqueness of each construction process, the conventional structure of the construction process which considers time, cost and quality as the main objectives of the construction process, and the lack of registered data about environmental impacts of the process. Moreover, environmental performance of the construction process is not a familiar issue for the shareholders of the construction industry in Turkey. Therefore, it is important to develop a method that provides the environmental assessment of the construction process with ease by the decision makers and to raise awareness on this subject.

This paper presents an environmental performance assessment model for the building construction process, which can be used during architectural detailing to compare different design alternatives. The model is developed based on the argument that the relationship between construction technologies and environmental impacts make the environmental assessment of construction process possible [2]. Construction technology covers information, methods and tools, which are the basic inputs of the construction process. The model proposes a construction technology classification to define the distinctive characteristics that influence the environmental performance. The environmental performance parameters are defined as resources, ecosystem quality and human health regarding construction and environmental legislation. The model proposes a construction technology classification and a decision hierarchy based on the environmental parameters related with the construction process. Integrated multi criteria decision-making methods, Fuzzy Analytical Hierarchical Process (Fuzzy AHP) and Fuzzy Technique for Order Preference by Similarity to Ideal Solution (Fuzzy TOPSIS), are used for weighing the parameters and sorting design alternatives by decision makers. The model provides an environmental assessment of the building construction process during architectural detailing, when quantitative data about construction technologies cannot be obtained. Hence, in the context of the paper, an application of the model on floor design alternative of 
an office building project is presented to demonstrate the use of the model and to identify advantages and limitations of the assessment process.

\section{Development of the model}

The model is developed based on the argument that construction technologies have a direct relationship with environmental impacts of the construction process. Therefore, construction technology options are firstly classified. Then, environmental performance parameters are defined based on the current legislation, rating systems and environmental assessments tools and databases used by these tools.

\subsection{Construction technology classification}

Technology brings together information and the physical components required for the process, which also affects the relationships between inputs and outputs [3]. Construction technology includes information, methods (processes, activities, techniques) and tools (materials, equipment, labor), which are used for realizing the building [4] (Figure 1). While information is the intangible component, methods and tools are the tangible components that are directly effective on the environmental performance of the construction process [2].

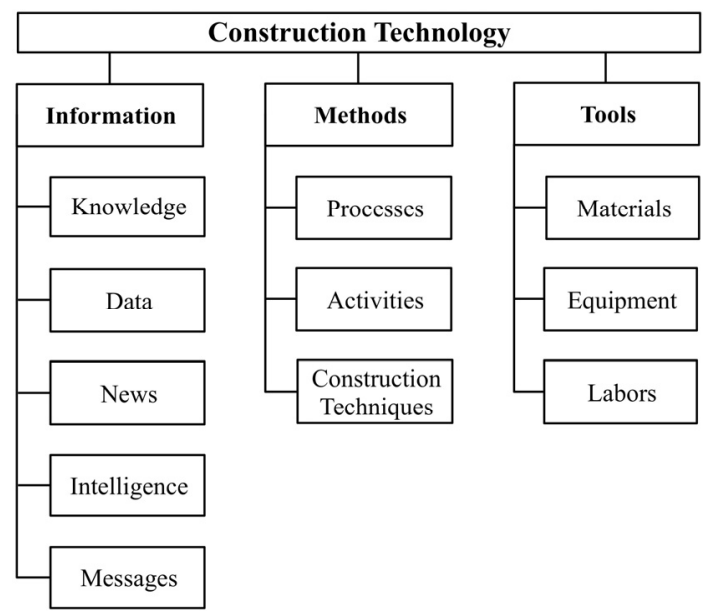

Figure 1: Construction technology classification.

Information consists of knowledge, data, news, intelligence and messages on the construction process [5]. The decision makers of the construction process investors, architects, engineers, project managers, general contractors, subcontractors - need different kinds of information in different phases of construction. The information required during the construction process can be gathered from building codes and regulations, standards, material catalogues, specifications, reports related to previous works, periodicals, books etc. [4]. 
Knowledge and data have a direct relationship with the environmental performance of the construction process, particularly. Knowledge is basically related with the environmental background and awareness of the decision makers. Data is related with the construction documents, such as construction project and quantity survey, which includes information about construction techniques, materials and equipment used for a specific construction process.

Methods consist of processes, activities and techniques that are used for realizing the building as a final product [6]. There are four basic processes for the construction process, such as transportation, formation and preparation of materials, and application of building elements, which are carried out by realizing transportation, formation, preparation and application activities. At this point construction techniques are defined as formation, preparation and application of materials on site.

Tools consists of physical inputs, materials, equipment and labor, which are required for realizing a building. Materials have a variety of options due to performance requirements they should meet, such as structural stability, weatherproofing, durability, thermal performance, movement, noise barrier, fire resistance, security [7]. Materials can be classified as basic, supplementary and joining materials according to their function within a building element. Equipment is defined as any machine, device, plant and facility, which is necessary for completing a task [8]. It can be classified according to the processes and the activities performed during the construction process. Transportation vehicles are used for transportation and handling the materials within construction site. The materials are formed and prepared by using various formation and preparation devices before the application process. Application devices are required to bring together basic and supplementary materials. All of the equipment is also classified according to their operation principles as human powered, fossil fuel based and electrically driven, which is important when the environmental issues are the subject. Labor can be defined according to the hierarchical order or specialty type. They can be classified as unskilled labor and skilled labor, while there are variety of labor type according to the specialty, such as roofer, plumber, etc. [9].

\subsection{Environmental performance parameters}

The regulations and standards define the parameters that should be used for an environmental assessment of services and products. Environmental impacts are defined as any change to the environment, whether adverse or beneficial, wholly or partially resulting from an organization's environmental aspects that are an organization's activities or products or services interacting with the environment $[10,11]$. Hence, an environmental indicator of a building addresses an environmental aspect either in terms of loadings or impacts, which are the use of resources and the production of waste, odors, noise and harmful emissions to land, water and air [12]. Moreover, the environmental performance of a building can be indicated with reference to environmental impacts caused by the building and/or building process and it is directly related with the effective use of methods and tools that support the consideration of environmental aspects [12]. 
Various environmental assessment methods and databases that are used for assessment such as IMPACT 2002+ vQ2.2, Eco-indicator 99, ReCiPe 2008, consider environmental impacts basically in three categories as damage, mid-point and end-point categories [13-15]. IMPACT 2002+vQ2.2, describes the damage categories as "Human Health", "Ecosystem Quality", "Climate Change" and "Resources" related with the variety of midpoint categories as human toxicity, respiratory affects, ionizing radiation, ozone layer depletion photochemical oxidation, aquatic and terrestrial eco-toxicity, aquatic acidification and eutrophication, land occupation, global warming, nonrenewable energy and mineral extraction [13, 16, 17]. The Eco-indicator 99, classifies the damage categories as "Damage to Resources", "Damage to Ecosystems" and "Damage to Human Health", which are assessed through resource, land use and emission analyzes [14]. ReCiPe 2008, involves indicators at midpoint and endpoint levels. Endpoint indicators are designated as "Human Health", Ecosystem Species" and "Resources" and variety of midpoint indicators are related to each endpoint category are defined, such as climate change, ozone depletion, acidification, eutrophication, toxicity, ionizing radiation, land-use, water depletion, mineral resource and fossil fuel depletion [15].

Therefore, the construction process is taken into account as the environmental aspect of a specific construction project, which includes variety of activities resulting from adverse environmental impacts. Damage Categories (DM), Midpoint Categories (MC) and Environmental Performance Parameters (EP) are defined based on the previously explained standards, databases and Turkish Regulations on Waste Management [18], Controlling the Packaging Waste [19], Controlling the Dust [20], Protection of Workers from Risks Related to Noise [21] and Protection of Workers from Risks Related to Vibration [22] (Table 1).

Table 1: Environmental performance parameters.

\begin{tabular}{lll}
\hline \multicolumn{1}{c}{ Damage categories } & \multicolumn{1}{c}{ Midpoint categories } & \multicolumn{1}{c}{$\begin{array}{c}\text { Environmental performance } \\
\text { indicators }\end{array}$} \\
\hline \multirow{2}{*}{ DC1 Resources } & MC1 Nonrenewable energy & EP1 Fossil fuel consumption \\
\cline { 2 - 3 } & MC2 Renewable energy & EP2 Electricity consumption \\
\hline \multirow{2}{*}{ DC2 Ecosystem Quality } & MC3 Natural resources & EP3 Water consumption \\
\cline { 2 - 3 } & MC4 Terrestrial ecotoxicity & \multirow{2}{*}{ EP4 Solid waste generation } \\
\cline { 2 - 3 } & MC5 Aquatic ecotoxicity & \\
\hline \multirow{2}{*}{ DC3 Human Health } & MC6 Human toxicity & EP5 Dust/particle generation \\
\cline { 2 - 3 } & MC7 Public health effect & EP6 Noise generation \\
\cline { 2 - 3 } & & EP7 Vibration generation \\
\hline
\end{tabular}

\section{The model}

The model is developed based on the relationship within construction technologies, and between construction technologies and environmental performance parameters (as shown in Figure 2). Material preferences affect 
construction technique options, which define required equipment for the construction, in return. The decision maker(s) should have information about other construction technology components to be able to support their decisions. While materials and equipment have direct relationships with environmental performance parameters, information, construction techniques and labor have indirect relationships.

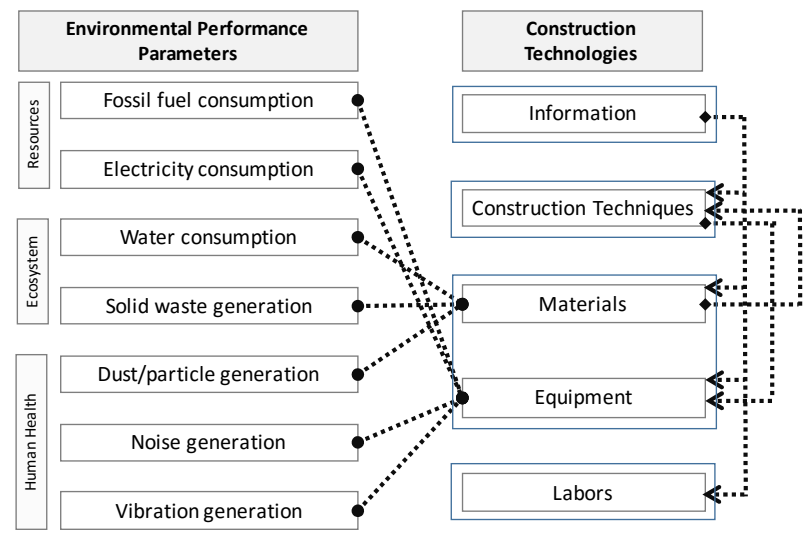

Figure 2: The relationships between environmental performance parameters and construction technologies.

After defining these relationships, the method of the model is designated. When assessment of alternatives and making a decision through them based on a specific goal is a concern, a scoring system is necessary to be able to weigh assessment criteria and the alternatives. This study tackles the problem of assessing different design alternatives based on their environmental performance at the construction process based on defined parameters and the goals of the decision makers. The defined environmental performance assessment parameters for the developed model have a hierarchical order, which enables using multi criteria decisionmaking methods (MCDM). Therefore, after analyzing different methods, Integrated Fuzzy Analytical Hierarchical Process (FAHP) and Fuzzy Technique for Order Preference by Similarity to Ideal Solution (FTOPSIS) methods are selected to be used in the context of the model.

FAHP is used to define weights of the parameters by decision maker(s) through pairwise comparisons, while FTOPSIS is used to rank design alternatives based on the decision maker(s)' assessment of alternatives and weight of the parameters. FAHP and FTOPSIS methods integrate fuzzy numbers into an assessment scale, which enables assessment in a subjective environment, and also to provide using linguistic statements instead of numerical ones, which makes judgment easier for the decision makers. The model is developed by following the steps below [2325]:

1. Decision problem of the model is designated as analyzing environmental performance of the building construction process during the architectural detailing process, when quantitative data about the construction process is not 
available. The main goal is sorting detail design alternatives according to their environmental performances during the construction process based on the decision maker(s) environmental expectations and concerns.

2. The Damage Categories (DC) and the Environmental Performance Indicators (EP) are included in the model as the decision criteria of the environmental performance decision-making. Midpoint Categories (MC) are not included in the model as they only define impact level which is caused by the EPs.

3. The detail designs' alternatives belong to a specific building element, e.g. floor system, external wall system etc., are defined as the decision alternatives.

4. The hierarchical structure of the decision-making constituted (Figure 3).

5. Decision makers are designated as owner, architects and contractor, who are directly involved in the design process. Owner cannot be involved in the decision process, if he/she does not have a background of environmental knowledge.

6. The data regarding construction technique, material and equipment are gathered from construction documents.

7. The pairwise comparisons are performed for the DCs and the EPs by the decision maker(s) using linguistic statements (as shown in Table 2).

8. Design alternatives are assessed by the decision maker(s) with respect to the DCs and the EPs using linguistic statements (as shown in Table 2).

9. Mathematical calculations of FAHP are performed to calculate the weight of the DCs and the EPs using the fuzzy triangular numbers given in Table 2.

10. Mathematical calculations of FTOPSIS are performed using the fuzzy triangular numbers given in Table 2 to sort design alternatives based on the weight of the DCs and the EPs.

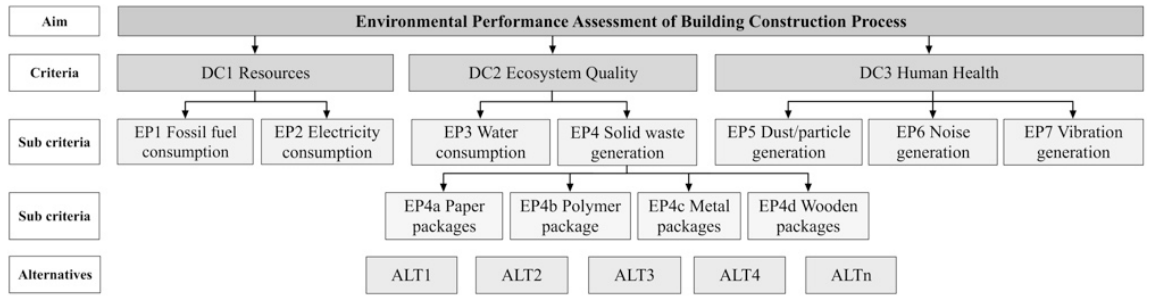

Figure 3: The hierarchical structure of the decision-making model.

Table 2: $\quad$ Linguistic statements and related fuzzy triangular numbers.

\begin{tabular}{llc}
\hline FAHP & FTOPSIS & $\begin{array}{c}\text { Fuzzy triangular } \\
\text { numbers }\end{array}$ \\
\hline Equally important & Equally effective & $(1,1,1)$ \\
\hline Weakly important & Weakly effective & $(2,3,4)$ \\
\hline Fairly important & Fairly effective & $(4,5,6)$ \\
\hline Strongly important & Strongly effective & $(6,7,8)$ \\
\hline Absolutely important & Absolutely effective & $(9,9,9)$ \\
\hline
\end{tabular}




\section{Application of the model}

The developed model is used to assess different floor alternatives of an office building project for validation, especially from the decision maker(s)' perspective, and to demonstrate the use of the model. The selected project has three floor system design alternatives for office spaces (as shown in Table 3 ).

Table 3: The assessed floor system alternatives.

\begin{tabular}{|c|c|c|}
\hline & & Basic and supplementary materials \\
\hline \multirow{3}{*}{ 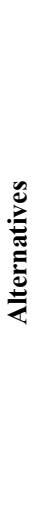 } & Alternative-1 & $\begin{array}{l}\text { - Artificial precast floor tile }(20 \mathrm{~mm}) \\
\text { - Adhesive }(8 \mathrm{~mm}) \\
\text { - Screed }(42 \mathrm{~mm}) \\
\text { - Reinforced concrete slab }(270 \mathrm{~mm})\end{array}$ \\
\hline & Alternative-2 & $\begin{array}{l}\text { - Linoleum covered panel }(40 \mathrm{~mm}) \\
\text { - Metal pedestal for raised floor system } \\
\text { - Dust free epoxy paint } \\
\text { - Reinforced concrete slab }(270 \mathrm{~mm})\end{array}$ \\
\hline & Alternative-3 & $\begin{array}{l}\text { - Ceramic floor tile }(8 \mathrm{~mm}) \\
\text { - Ceramic adhesive }(5 \mathrm{~mm}) \\
\text { - Cement-acrylic based liquid waterproofing } \\
\text { - Screed with mesh reinforcement }(50 \mathrm{~mm}) \\
\text { - Aerated concrete filling }(137 \mathrm{~mm}) \\
\text { - Reinforced concrete slab }(270 \mathrm{~mm})\end{array}$ \\
\hline
\end{tabular}

The head of the design team, who is also responsible for on-site supervision, was assigned as the decision maker of the assessment process. The Respondent is an architect with a master's degree and has a background in environmentally conscious design. First, the Respondent was informed about the research subject and the use of the model through a presentation. Then, the Respondent was asked to perform pairwise comparisons for the DCs and the EPs forms and to assess three floor system alternatives with regard to each DC and EP through an interview.

Finally, mathematical calculations for FAHP and FTOPSIS methods were performed. The method, developed by Buckley [24] was used for FAHP calculations, and FTOPSIS calculations were performed by following the steps Shukla et al. [25] propose.

\section{Results and discussion}

The weights of the parameters based on the Respondent's environmental priorities and concerns, and the rank of the alternatives (A) based on the Respondent's assessment of the alternatives for each Damage Categories (DC) and Environmental Performance Indicators (EP) are given in Table 4.

The Respondent's pairwise comparisons reveal that Ecosystem Quality and Human Health have equal and uttermost importance, while Resources take the second place according to the Respondent's concerns about Damage Categories. 
Table 4: Results of the assessment process.

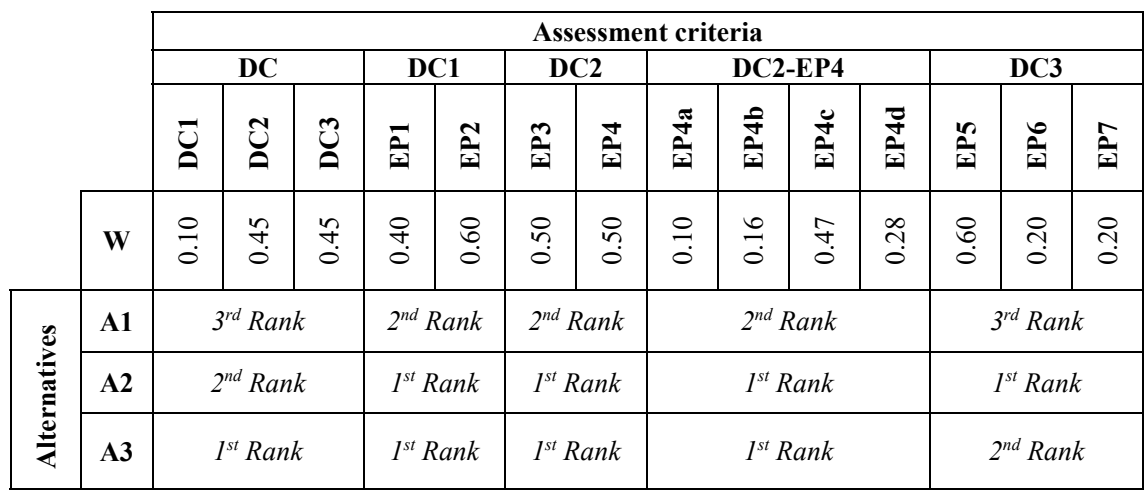

DC: Damage Categories. DC1: Resources. DC2: Ecosystem Quality. DC3: Human Health. EP1: Fossil Fuel Consumption. EP2: Electricity Consumption. EP3: Water Consumption. EP4: Solid Waste Generation. EP4a: Paper Packages. EP4b: Polymer Packages. EP4c: Metal Packages. EP4d: Wooden Packages. EP5: Dust/Particle Generation. EP6: Noise Generation. EP7: Vibration Generation. W: Weight.

Electricity Consumption is accepted as the most important resource type consumed during the construction process by the Respondent. Water Consumption and Solid Waste Generation have equal importance, while Metal, Wooden, Polymer and Paper Waste have importance at decreasing grades, respectively due to the waste management principles of the relevant construction site. Dust/Particle Generation gets the highest importance, while Noise and Vibration Generation have equal importance.

According to all the Damage Categories, A3 causes the most adverse environmental impacts during the construction process, while A1 has the lowest effect and A2 has an average effect compared to A1 and A3. A2 and A3 have the same and worst adverse impact on Resources Ecosystem Quality and Solid Waste Generation, and A2 takes second place. A2, A3 and A1 cause negative impacts on Human Health, respectively.

When the results are analysed by taking into account the construction technologies involved during the construction process of the alternatives, it can be said that the basic characteristics of the alternatives cause these results. For instance, A1 and A2 involve adhesives and screeds, and require on site preparation for the application. The preparation process causes dust, noise and vibration due to characteristics of the joining materials and electrical tool usage. A3 mostly includes electrical tool usage for the application. Vehicles, which consume fossil fuel, are used for the transportation and handling of all materials on site.

\section{Conclusion}

The proposed model aims to assess design alternatives based on their environmental performances during the construction process. The results show that the model can be used to make assumptions about the environmental performance of the construction process at design phase by gathering information 
from construction documents and using knowledge that decision makers have about environmental issues and the relevant design alternatives. When a decision maker is informed about the environmental performance of the construction process and the use of the model, he/she can define his/her own priorities or concerns regarding with the environmental performance of the construction process by taking into account the characteristics of the construction site in question and assess different design alternatives. On the other hand, decision maker(s) should be well informed about the assessment parameters, construction technology classification, the relationship among them and the virtue of the pairwise comparisons to avoid or to lessen bias and conflicts on both the model and the results. The learning process of the model also enables decision maker(s) to recognize environmental consequences of the building construction process and guide them through taking possible measures. The conflicting issues related with the construction process, such as time and cost, can make it impossible to select the best option among the alternatives that the model reveals. However, assessment results can provide an insight to decision makers for enhancing design alternatives.

\section{References}

[1] Pollo, R. \& Rivotti, A., Building sustainability evaluation in the building process: The construction phase. Proceedings of The Regional Central and Eastern European Conference on Sustainable Building, Building Research Institute: Warsaw, Poland, CD-ROM, 2004.

[2] Metin, B. \& Tavil, A., The relationship between construction technologies and environmental impacts. Proceedings of 40th IAHS World Congress on Housing, Funchal, Portugal, 2014.

[3] Utkutuğ, G., A Conceptual Model for Obtaining Alternative Construction Methods in the Context of Appropriate Technology (in Turkish). Istanbul Technical University: Istanbul, 1981.

[4] Edis, E., A Method to Design Architectural Constructional Elements (in Turkish), Istanbul Technical University, Graduate School of Science, Engineering and Technology: Istanbul, Ph.D. Thesis, 2006.

[5] Kanoğlu, A., Information System Design and Application In Construction Industry (Unpublished Lecture Note), İstanbul, 2010.

[6] Türkçü, Ç.H., Construction: Principles-Materials-Methods-Solutions (in Turkish), Birsen Publishing: Istanbul, 2004.

[7] Rich, P. \& Dean, Y., Principles of Element Design, Architectural Press: Oxford, 1999.

[8] Ministry of Environment and Urban Planning. Health and Safety Requirements Regulation for the Use of Work Equipment, Prime Ministry General Directorate of Legislative Development and Publication, Ankara, 2013. http://www.resmigazete.gov.tr/eskiler/2013/04/20130425-7.htm

[9] Ministry of Environment and Urban Planning. Construction and Installation Unit Price Library of Turkey, 2014. http://www.birimfiyat.net/ 
[10] BS EN ISO 14001: Environmental management systems - Requirements with guidance for use. The British Standards Institution, 2004.

[11] ISO 21931-1: Sustainability in building construction - Framework for methods of assessment of the environmental performance of construction works - Part 1: Buildings. Vol. 2010. The British Standards Institution, 2010.

[12] ISO/TS 21929-1: Sustainability in building construction - Sustainability indicators - Part 1: Framework for the development of indicators for buildings. Vol. 2006. The British Standards Institution, 2006.

[13] Humbert, S., De Schryver, A., Bengoa, X., Margni, M. \& Jolliet, O., IMPACT $2002+$ : User Guide. 2002.

[14] Ministry of Housing, Spatial Planning and the Environment. Eco-indicator 99 Manual for Designers, 2000. http://www.pre-sustainability.com/ download-/manuals/EI99_Manual.pdf

[15] Goedkoop, M., Heijungs, R., Huijbregts, M., De Schryver, A., Stryijs, J. \& van Zelm, R., ReCiPe 2008 - A Life Cycle Impact Assessment Method which comprises Harmonised Category Indicators at the Midpoint and the Endpoint Level, 2013. https://www.pre-sustainability.com/download/ manuals/ReCiPe

[16] Jolliet, O., Margni, M., Charles, R., Humbert, S., Payet, J., Rebitzer, G. \& Rosenbaum, R., IMPACT $2002+$ : A new life cycle impact assessment methodology. The International Journal of Life Cycle Assessment, 8(6), pp. 324-30, 2003.

[17] Udo de Haes, H.A., Jolliet, O., Finnveden, G., Hauschild, M., Krewitt, W. \& Müller-Wenk, R., Best available practice regarding impact categories and category indicators in life cycle impact assessment, The International Journal of Life Cycle Assessment, 4(2), pp. 66-74, 1999.

[18] Ministry of Environment and Urban Planning. Regulation on Waste Management, Official Journal of Turkish Republic: Ankara, 2015.

[19] Ministry of Environment and Urban Planning. Regulation on Controlling the Packaging Waste, Official Journal of Turkish Republic: Ankara, 2011.

[20] Ministry of Labor and Social Security. Regulation on Dust Control, Official Journal of Turkish Republic: Ankara, 2013.

[21] Ministry of Labor and Social Security. Regulation on the Protection of Workers from the Risks Related to Noise, Official Journal of Turkish Republic: Ankara, 2013.

[22] Ministry of Labor and Social Security. Regulation on the Protection of Workers from the Risks Related to Vibration, Official Journal of Turkish Republic: Ankara, 2013.

[23] Yıldırım, B.F. \& Önder, E., (eds). Multi Criteria Decision-Making Methods, Dora Publishing: Bursa, 2015.

[24] Buckley, J.J., Fuzzy hierarchical analysis, Fuzzy Sets and Systems, 17, pp. 233-247, 1985.

[25] Shukla, R.K., Garg, D. \& Agarwal, A., An integrated approach of Fuzzy AHP and Fuzzy TOPSIS in modeling supply chain coordination, Production \& Manufacturing Research: An Open Access Journal, 2(1), pp. 415-437, 2014. 